\title{
Nurses' Performance Regarding Preventive Measures Of Pulmonary Embolism In Port Said Hospitals
}

\author{
Amal Bakr Abo El-Ata ${ }^{1}$, ELSaida Gamal Baghdady ${ }^{2}$, Faten Ali Hassan Khedr ${ }^{3}$ \\ Assistant professor of medical surgical nursing - Faculty of Nursing Port Said \\ University $^{1}$; Lecturer of Medical Surgical nursing - Faculty of Nursing - Port Said \\ University $^{2}$; B.Sc. Nursing , Faculty of Nursing - Port Said University ${ }^{3}$
}

\begin{abstract}
Background: Pulmonary embolism is the third commonest cause of cardiovascular death after coronary artery disease and stroke .Preventing thrombus formation is a major nursing role. Therefore, the best management of pulmonary embolism is through prevention of risk factors. Aim: Assess nurses' performance regarding preventive measures of pulmonary embolism. Subjects and Method: A descriptive research design was used. Setting: The study was conducted in surgical department, orthopedic department and intensive care unit at Port-Said general hospital, PortFouad general hospital, and Elzohour hospital. Subjects: A convenient sample of 90 nurses were participate in the study Tools: Data were collected using three tools, Nurses' Knowledge questionnaire, observational check list for nurses' practice and Nurses 'attitude scale. Results: The result of study indicated that $71.1 \%$ of studied nurses had unsatisfactory knowledge, $62.2 \%$ had unsatisfactory practice and $74.4 \%$ had positive attitude regarding preventive measures of pulmonary embolism Conclusion: The studied nurses had unsatisfactory level of knowledge and practice, but, remarkable positive attitude was observed regard the preventative measures of pulmonary embolism. Also there was statistical significant correlation between nurses' knowledge and practice .Recommendations: There are obvious needs for conducted an in service educational and training programs to improve nurses' performance regarding preventive measures of pulmonary embolism.
\end{abstract}

Key Words: Pulmonary embolism, Preventive measures, Nurses' performance 


\section{INTRODUCTION}

Pulmonary embolism is third most common cause of cardiovascular death worldwide after stroke and heart attack. Pulmonary embolism PE is a significant cause of hospitalization morbidity and mortality and frequently triggers referral to critical care services. PE is the blockage of one or more branches of the pulmonary artery resulting in lack of perfusion to the alveoli. The risk of developing a thrombus is often described with Virchow's triad, which includes venous stasis, endothelial injury, and hypercoagulability of the blood. (Oh, Boo \&Lee, 2017 ; Stone, Hangge \& Albadawi, 2017)

Pulmonary embolism as a subsequent event after DVT is critical and is one of the leading causes of death for many patients. Most PEs originates from DVTs of lower extremities, and approximately 50\% of DVT may lead to silent PE. Therefore, the nursing profession should make progress on the assessment and prevention of VTE in all hospitalized patients. Despite the better awareness of this serious condition, the diagnosis is still overlooked in many cases with sometimes fatal consequences. (Essien, Rali , Mathai\& 2019)

Early diagnosis and treatment of PE reduces morbidity and mortality If not treated early, a pulmonary embolism can be life-threatening. About one-third of people with undiagnosed or untreated pulmonary embolism die from the condition. Early treatment greatly reduces the risk of death. (Heit, 2015)

Prevention is the primary goal of nursing care for patients at risk for developing PE. The best management of pulmonary embolism is through prevention of DVT. Deep venous thrombosis must be used routinely for any hospitalized patients. The nurse must recognize risk factors for pulmonary embolism and vigilantly monitor patients who are immobilized or have had their activity restricted for unexplained tachypnea, tachycardia, and restlessness. These signs must not be attributed to anxiety unless a physical cause has been sought first.

(Timby \& smith.,2014)

Many preventive interventions best nursing practices for prevention from PE are starting active and passive range-of motion exercises for the extremities of immobilized patients postoperative surgery, ambulating patients soon after surgery, using anti embolism and pneumatic compression stockings and devices after surgery, avoiding the use of constricting clothing, performing a comprehensive assessment of peripheral circulation, changing patient position every 2 hours ,performing leg exercise, administering prescribed prophylactic low- dose anticoagulant and antiplatelet drugs and encouraging smoking cessation. Once a preventive plan is in place, evaluate the patient's response to interventions and adjust them as necessary. (Linda \& Ignatavicius, 2013) 
Nurses need to be taught how to evaluate all sources of knowledge and must learn how to become critical thinkers, as this will increase the quantity and quality of nursing knowledge. Nurses also need, perhaps, to think about the elements of practice and learning from experience. It seems that reflective practice in vogue. (Mohammed, Hamdan, Ali, Aaly, \& Hadi,2017)

Because pulmonary embolism can be medical emergency, assessment may be much focused. therefore, this study will be conducted to assess nurse's performance toward patients for preventing from pulmonary embolism in port said hospitals. (Lemone, Burke, Dwyer, Jones \& Moxham.,2014)

\section{Significance of study:}

After coronary artery disease and stroke, acute PE ranks third among the most common types of cardiovascular diseases. While clinical data indicate that most cases of PE occur at 60 to 70 years of age, autopsy data show the highest incidence among individuals 70 to 80 years of age. If untreated, acute PE is associated with a significant mortality rate (as high as $30 \%$ ), whereas the death rate of diagnosed and treated PE is $8 \%$. Up to $10 \%$ of acute PE patients die suddenly. Two of three patients succumbing to PE die within $2 \mathrm{~h}$ after presentation. (Linhart,2018).

According to Agency of healthcare Research and Quality; (2015) Deep Vein Thrombosis and Pulmonary embolism affect an estimated 300,000 to 600,000 people per year and may directly cause more than 100,000 deaths and contribute to another100,000 deaths each year .

Prevention of PE begins with prevention of DVT. In many cases, DVT has not been recognized or treated. Often embolization also goes undetected. Prevention is the most effective treatment strategy for pulmonary embolism, Therefore, the nurse must have a degree of suspicion for PE in all patients, but particularly in those with conditions predisposing to venous stasis. Therefore, the need to improve PE risk assessment and prophylactic practices in the hospital setting is important. (Lemone et al., 2014)

\section{AIM OF THE STUDY:}

This study aims to assess nurses' performance regarding preventive measures of pulmonary embolism at Port Said hospitals.

This aim achieved through

1- Assess nurses' knowledge regarding preventive measures of pulmonary embolism at Port Said hospitals.

2- Assess nurses' practice regarding preventive measures of pulmonary embolism at Port Said hospitals. 
3- Assess nurses' attitude regarding preventive measures of pulmonary embolism at Port Said hospitals.

\section{SUBJECTS AND METHOD:}

\section{Research Design}

A descriptive study design was used to conduct the study.

\section{Study Setting}

This study was conducted at three hospitals affiliated to the ministry of health Port-Said general hospital, Port-Fouad general hospital, and Elzohour hospital from each hospital, the following units are included; surgical department, orthopedic department and intensive care unit.

\section{Study sample:}

Convenient sample of all available nurses. Work in previous mentioned Setting it consisted of 90 nurses. Port-Said General Hospital 54 nurses, Port-Fouad General Hospital 19 nurses and Elzohor General Hospital 17 nurses.

\section{Tools for data collection}

\section{Three tools were used for data collection}

\section{Tool I: Nurses' knowledge questionnaire}

It was designed by the researcher after reviewing of the recent related literatures (Lewis \&Pilcher.,2016; Timby \&Smith.,2014; Cooray \&Lake,.2018) to assess nurses' knowledge regarding preventive measures of pulmonary embolism. It was consisted of three parts as the following:

\section{Part 1: Demographic characteristics}

It was concerned with demographic characteristics of studied nurses and included age, sex, qualification.

\section{Part 2: - Work related data}

It was concerned with work related data of studied nurses and included hospital name, years of experience, attending training courses regarding preventive measures of pulmonary embolism. 


\section{PART 3: Nurses' Knowledge questionnaire: -}

It was consisted of 30 questions 15 of them closed ended questions to identify nurses' level of knowledge about pulmonary embolism including: definition, causes, risk factors, signs \&symptoms, diagnosis, preventive measures pre, intra and postoperative phase, treatment and complication. in addition to 15 questions in the form of true or false. The studied nurses'answers is compared with model key answer, where one (1) scores are given to correct answer and (zero) for incorrect answer, their knowledge was considered "satisfactory" if the percent score was $70 \%$ or higher and "unsatisfactory" if less than $70 \%$.

\section{TOOL II: Nurses' Practice Observational checklist:}

This tool was developed by the researcher based on standardized nursing skills reviewed from related literature (Lynn, 2015; Potter, Patricia, \& Perry, 2013 \& Timby, 2017) to measure nurses'practice of nurses regarding preventive measures of pulmonary embolism. 12 items used to assess respiration, 13 items about perform deep breathing exercise, 19 items assess ambulation, 17 items perform leg exercise, 16 items perform turning in bed and18 items apply compression elastic stocking regarding preventive measures of pulmonary embolism, where done take (1) score and not done take (zero) score. These scores were converted into a percent score, according to the nurses' actual practice, their level of practice was considered "satisfactory" if the percent score was $70 \%$ or more and "unsatisfactory" if less than $70 \%$.

\section{Tool III: Nurses' Attitude scale}

This tool is developed by the researcher based on reviewing of recent related literature review. The tool consisted of (13) attitudinal statements regarding preventive measures of pulmonary embolism. The attitudinal items are both positively and negatively worded to force respondents to read each statement and respond appropriately. They are measured on five-point Likert scale ranging from ( zero) to ( four) as (zero) for never, one (1) for little, two (2) score for sometimes, three (3) for often, and four (4) score for always, for the positive attitude number $(1,2,4,5,7,8,9,10,12,13)$ and the negative attitude number(3,6,11) for the 13 statement . The attitude scale included both positive and negative item statements. Total scores that be achieved ranged from 0 to 46 scores are considered positive if the percent score was $70 \%$ or more and negative if less than $70 \%$.

\section{Pilot study:}

The pilot study is carried out on 10 nurses (10\%) of total number of nurses who have been working at Port-Said general hospital, Port-Fouad general hospital, and Elzohor general hospital to test applicability, clarity, relevance and feasibility of study tool to detect sequence of quotations to maintain consistency and estimate the time 
needed to complete the tools. The necessary modifications are done and the final form is developed .The nurses in the pilot study are excluded from the final subjects of the study.

\section{Field work}

Data were collected from available nurses who have been working at previously mentioned settings. The process was carried out from the beginning of March 2018 to the end of May 2018. The researcher has met the nurses individually and explains to them purpose of the study and obtains oral consent. Nurses were observed during usual work in different shifts. The usual work begin with measuring vital signs then nurses were observed through assessing respiration ,applying leg exercise ,elastic stockings were performed for bedridden patients. The time needed to complete the checklist varies ranged between 15-20 minutes. Every postoperative patient was instructed to perform deep breathing exercise and move out bed after surgical operation. Nurses were observed for two hours at beginning of each shift or morning shift then the researcher was asked to fulfill the questionnaire. Then giving them the questionnaire and attitude scale to fill it. It takes 30 minutes to fill the questionnaire from the researcher.

\section{ADMINISTRATIVE DESIGN}

A formal letter from the Dean of the Faculty of nursing Port Said university was submitted to the directors of Port-Said general hospital, Port-Fouad general hospital and Elzohour general hospital to take permission to collect data. The aim of the study and procedures were explained to them to attain their cooperation.

\section{Ethical considerations:}

The aim of the study was simply explained to the nurses. An oral explanation was obtained from nurses who agree to participate in the study prior to data collection. They were assured that anonymity and confidentiality would be guaranteed and the right of nurses to withdraw at any time. Ethics, values, culture and beliefs was respected.

\section{Statistical analysis:}

Data collected were arranged, tabulated and analyzed according to the type of each data. Data were fed to the computer and analyzed using IBM SPSS software package version 20.0. (Armonk, NY: IBM Corp). Data were presented using statistics in the form of frequencies and percentages for qualitative variables. 


\section{RESULTS:-}

Table (1): represent demographic characteristics of studied nurses about three quarter of studied nurses $74.4 \%$ in age group from 20 to less than 30 years old. The majority of studied sample $88.9 \%$ were female, and $45.6 \%$ were graduated from nursing technical institute.

Table (2): describes work related data of studied nurses, the table shows that $60 \%$ of the studied nurses were from port -said general hospital, and all of Nurses hadn't any training courses $100 \%$ related to preventive measures of pulmonary embolism .

Table (3): the table shows that $71.1 \%$ of studied nurses had unsatisfactory level of knowledge.

Table(4): represents the total nurses' practice regarding preventive measures of pulmonary embolism 93.3 of studied nurses the table shows that the most percentage of studied sample had satisfactory level of practice regarding the leg exercise. While $62.2 \%$ of studied nurses had unsatisfactory level of total practice level.

Table (5): represents that three quarter of studied nurses $74.4 \%$ had satisfactory level in their total score of attitudes, while $25.6 \%$ had unsatisfactory level regarding preventive measures of pulmonary embolism.

Table (6): illustrates correlation between knowledge, practice and attitude of studied nurses regard preventive measures of pulmonary embolism. The table proves that there was statistical significant positive correlation between nurses' knowledge and practice. The correlation between knowledge, attitude and attitude, practice was not significant. 


\section{RESULTS:-}

Table (1): Distribution of the studied nurses according to demographic characteristics $(\mathbf{n}=\mathbf{9 0})$

\begin{tabular}{||l|c|c||}
\hline Demographic characteristics & No. & $\%$ \\
\hline Age (years) & 67 & 74.4 \\
$20-<30$ & 19 & 21.1 \\
$30-<40$ & 2 & 2.2 \\
$40-<50$ & 2 & 2.3 \\
$50-60$ & & \\
Sex & 10 & 11.1 \\
Male & 80 & 88.9 \\
Female & 37 & 41.1 \\
Qualification & 41 & 45.6 \\
Nursing Diploma & 12 & 13.3 \\
Nursing technical Institute & & \\
Bachelor of nursing & & \\
\hline
\end{tabular}

Table (2): Distribution of the studied nurses according to work relate $(\mathrm{n}=90)$

\begin{tabular}{|c|c|c|}
\hline Work related data of studied nurses & No. & $\%$ \\
\hline Hospital name & \multirow[b]{2}{*}{54} & \multirow[b]{2}{*}{60.0} \\
\hline Port-Said general hospital & & \\
\hline Port-Fouad general hospital & 19 & 21.1 \\
\hline Elzohor central hospital & 17 & 18.9 \\
\hline Years of experience in nursing in selected places & \multirow[b]{2}{*}{38} & \multirow[b]{2}{*}{42.2} \\
\hline$<5$ years & & \\
\hline $5-<10$ years & 30 & 33.3 \\
\hline $10-<20$ years & 19 & 21.1 \\
\hline$\geq 20$ years & 3 & 3.3 \\
\hline $\begin{array}{l}\text { Attend training courses to prevent pulmonary } \\
\text { embolism }\end{array}$ & \multirow[b]{2}{*}{90} & \multirow[b]{2}{*}{100} \\
\hline No & & \\
\hline
\end{tabular}


Table (3): Distribution of the studied nurses according to their nurse's knowledge regarding preventive measures of pulmonary embolism $(\mathrm{n}=90)$

\begin{tabular}{||l|c|c|c|c||}
\hline \multirow{2}{*}{ Variable } & \multicolumn{2}{c|}{ Unsatisfied } & \multicolumn{2}{c|}{ Satisfied } \\
\cline { 2 - 5 } & No. & $\%$ & No. & $\%$ \\
\hline $\begin{array}{l}\text { Knowledge } \\
\text { Nurses knowledge regarding to pulmonary } \\
\text { embolism }\end{array}$ & 58 & 64.4 & 32 & 35.6 \\
$\begin{array}{l}\text { Preventive measures of pulmonary } \\
\text { embolism }\end{array}$ & 52 & 57.8 & 38 & 42.2 \\
\hline \multicolumn{1}{|c|}{ Total knowledge } & $\mathbf{6 4}$ & $\mathbf{7 1 . 1}$ & $\mathbf{2 6}$ & $\mathbf{2 8 . 9}$ \\
\hline \hline
\end{tabular}

Table (4): Distribution of the total nurses' practice regarding preventive measures of pulmonary embolism $(\mathrm{n}=90)$

\begin{tabular}{||l|c|c|c|c||}
\hline \multirow{2}{*}{ variable } & \multicolumn{2}{|c|}{ Unsatisfied } & \multicolumn{2}{c|}{ Satisfied } \\
\cline { 2 - 5 } & No. & $\mathbf{\%}$ & No. & $\mathbf{\%}$ \\
\hline Respiration & 36 & 40.0 & 54 & 60.0 \\
Deep breathing & 47 & 52.2 & 43 & 47.8 \\
Ambulation & $\mathbf{6 7}$ & $\mathbf{7 4 . 4}$ & 23 & 25.6 \\
Leg exercise & 6 & 6.7 & $\mathbf{8 4}$ & $\mathbf{9 3 . 3}$ \\
Turning bed & 44 & 48.9 & 46 & 51.1 \\
Ant embolic elastic & 38 & 42.2 & 52 & 57.8 \\
\hline \multicolumn{1}{|c|}{ Total } & $\mathbf{5 6}$ & $\mathbf{6 2 . 2}$ & $\mathbf{3 4}$ & $\mathbf{3 7 . 8}$ \\
\hline
\end{tabular}

Table (5): Distribution of the studied nurses according to total nurses' attitude regarding preventive measures of pulmonary embolism $(\mathbf{n}=\mathbf{9 0})$

\begin{tabular}{||c|c|c|c|c||}
\hline \multirow{2}{*}{ Variable } & \multicolumn{2}{|c|}{ Unsatisfactory } & \multicolumn{2}{c|}{ Satisfactory } \\
\cline { 2 - 5 } & No. & $\%$ & No. & $\%$ \\
\hline Total attitude & 23 & 25.6 & 67 & 74.4 \\
\hline
\end{tabular}


Table (6): Correlation between knowledge, practice and attitude towards preventive measures of pulmonary embolism of studied nurses $(n=90)$

\begin{tabular}{|l|c|c|}
\hline \multicolumn{1}{|c|}{ Variable } & r & p \\
\hline Knowledge VS attitude & -0.025 & 0.818 \\
\hline Knowledge VS practice & 0.207 & $0.051^{*}$ \\
\hline Attitude VS practice & 0.039 & 0.713 \\
\hline
\end{tabular}

r: Pearson coefficient

$\mathrm{p}$ value $\leq 0.05$

\section{DISCUSSION:}

Pulmonary embolism PE and deep venous thrombosis DVT are leading causes of preventable death and disability in the United States. Acute PE is the third most common acute cardiovascular disease, with about 600,000 cases annually (Carpenter, 2017 and Lee et al., 2014)

The findings of the present study denoted that, majority of the studied nurses had unsatisfactory level in their total scores of knowledge regarding to pulmonary embolism. This study in the same line with Abulwafa.,2011 who reported that majority of studied nurses had unsatisfactory level in knowledge regarding to pulmonary embolism.

This result agrees with (Oh et al.,2017) who stated that most of participants rated their VTE knowledge were fair or poor. This may be related to the low level of inservice continuous education regarding venous thromboembolism risk assessment and prevention.

The current study showed that the majority of the nurses had unsatisfactory knowledge regarding the pulmonary embolism-related content in their nursing curricula. This is obviously detected as the majority of them had incorrect knowledge regarding risk factors of pulmonary embolism, Causes of pulmonary embolism, diagnosis of pulmonary embolism, Symptoms of DVT, Symptoms of pulmonary embolism, complication of pulmonary embolism and precaution of treatment. 
The reasons for lack of nurses' knowledge regarding from the researchers' point of view" might be related to lack of continuing educational programs or sessions about pulmonary embolism, supervision, continuous evaluation of nurses' practice, and cooperation between multidisciplinary health care team members (nurses physicians). The researcher point of views is supported by Lexshimi, Daud, and Zulkifli., 2009 who mentioned that nurses need to improve their knowledge especially nurses' knowledge before, during and health education as responsibility for care of patients lies in the hands of nurses. Therefore, for nurses to provide high quality care and function effectively, they must have an adequate knowledge that they have actually used in practice. (Kasem, 2016)

Regarding Nurses' practice the current study showed that the majority of the nurses had unsatisfactory level in their total scores of practices regarding to preventive measures of pulmonary embolism. This study in the line with Abulwafa.,2011 who revealed that majority of nurses had inadequate performance toward patients with pulmonary embolism This might be related to the fact that gap in nursing practice is increased due to poor understanding, ignorance, lack of time, simply or lack of training and inadequacy of adherence to evidence-based guidelines, so there is a various need for performing VTE prevention and current practical guidelines.

In the light of the present study findings, there was statistically significant correlation between total scores of nurses' knowledge and practice towards preventive measures of pulmonary embolism. This result disagrees with Antony., 2016 mentioned that there was no significant association between the knowledge and practice of staff nurses on prevention of DVT among hospitalized patients. In spite of the study results which had average knowledge, when it comes to practice, it may be probably because there are no strict protocols making it evident the practice of these nursing measures to prevent DVT. This also emphasizes the importance of proper attitude in patient care. Also, (Ali.,2013) who revealed that no correlation what so ever between knowledge and practice. Lack of association between the total knowledge scores and performance scores may be partially interpreted in the light of lack of training courses, updating pre-existing knowledge, lack of time, workload, and lack of equipment as the reasons for noncompliance ventilator bundle practices. Also, (Kubilay\& Fesci Erdem,2012) who reported that nurses should provide enough 
information and monitor the personnel's practice in their workplace to improve their behaviors. In general, focus on nurse's education with new and innovative training methods is very effective. We should target personnel's knowledge and attitude together to change their practice and improve their behavior. This result wasn't consistent with (Khan, Khowaja , \& Ali ., 2012) who illustrate that, the overall finding of the study indicated that the participants have poor knowledge and skills, however their attitude is good. These findings might be related to deficiencies in nurses' knowledge and practice regarding to preventive measures of pulmonary embolism which can adversely affect patient safety and education. Training is considered one way of preventing adverse nursing outcomes. So, to provide high quality care, nurses must have an adequate knowledge that they have actually used in practice.

\section{CONCLUSION:}

The studied nurses had unsatisfactory level of knowledge and practice but remarkable positive attitude was observed regard the preventative measures of pulmonary embolism. Also, there was statistical significant correlation between nurses knowledge and practice. correlation between knowledge, practice and attitude of studied nurses regard preventive measures of pulmonary embolism. The table proves that there was statistical significant positive correlation between nurses' knowledge and practice. The correlation between knowledge, attitude and attitude, practice was not significant.

\section{RECOMMENDATIONS:}

In the light of the study results, the following recommendations are proposed:

- Provide nurses with continuous in service educational programs regarding to preventive measures of pulmonary embolism with evidence based guidelines to improve their knowledge and practice

- Provide nurses with periodic training sessions and evaluations to improve their practice and assess their knowledge and practices regarding to preventive measures of pulmonary embolism .

- Replication of this study on a larger probability sample from the different geographical locations at the Arab Republic of Egypt and further research to 
explore why nurses do not always have the appropriate knowledge or skills regarding to preventive measures of pulmonary embolism .

\section{REFERENCES :-}

Abulwafa,M( 2011): Assessment of Nurses' knowledge and Performance toward Patients with Pulmonary Embolism Unpublished Master thesis. Faculty of Nursing, Assuit University.10.13140/RG.2.2.35019.59680

Agency of Healthcare Research and Quality ، (2015): Preoperative pulmonary embolism or deep vein thrombosis (DVT).retrived from http/www.cms.gov/outresearch-and-Education /medi carelearningNetwork/MLNP/ MLNP products downloads lwpoa -fact sheet -pdf

Ali, N. S. (2013). Critical Care Nurses' knowledge and compliance with ventilator associated pneumonia bundle at Cairo university hospitals. Critical Care, 4(15).

Said, A. T. (2012). Knowledge and practice of intensive care nurses on prevention of ventilator associated pneumonia at Muhimbili national hospital, Dar es Salaam, Tanzania (Doctoral dissertation, Muhimbili University of Health and Allied Sciences).

Antony, A. M., Moly, K. T., \& Dharan, D. R. (2016). Assessment of knowledge and self reported clinical practice on prevention of Deep Vein Thrombosis (DVT) among staff nurses. IOSR Journal of Nursing and Health Science, 5(1), 18-24.

Asma, A. (2006). Knowledge on prevention on DVT. Am HeurtJ, 122,478-482. Retrieved from : http://www.ncbi.nlm.nih.gov/pubmed/1858629

Bělohlávek, J., Dytrych, V., \& Linhart, A. (2013). Pulmonary embolism, part I: Epidemiology, risk factors and risk stratification, pathophysiology, clinical presentation, diagnosis and nonthrombotic pulmonary embolism. Experimental \& Clinical Cardiology, 18(2), 129. 
Carpenter, N. (2017). Massive Pulmonary Embolism and ThrombolyticTherapy: Case Study. Journal of Diagnostic Medical Sonography, 33(3), 232-238

Cooray, R., \& Lake, C. (2018). Prevention of deep vein thrombosis and pulmonary embolism. Anaesthesia \& Intensive Care Medicine, 19(9), 480-485 Carpenter, N. (2017). Massive Pulmonary Embolism and Thrombolytic Therapy: Case Study. Journal of Diagnostic Medical Sonography, 33(3), 232-238.

Cook , D., Mullin , M., Hodder, R., \& Stewort, T. (2001). Preventionand Diagnosis of DVT in Critically I11 Patients: a Canadian survey. Crit Care., 5(6), 42-336.

Cross, R., Bennett, P. N., Ockerby, C., Wang, W. C., \& Currey, J. (2017). Nurses' Attitudes Toward the Single Checking of Medications. Worldviews on Evidence-Based Nursing, 14(4), 274-281.

Essien, E.-O., Rali, P., \& Mathai, S. C. (2019). Pulmonary Embolism. Medical Clinics of North America, 103(3), 549-564. doi:10.1016/j.mcna.2018.12.013

Gorski, L. A. (2007). Venous Thromboembolism: A Common and Preventable ConditionImplications for the Home Care Nurse. Home Healthcare Now, 25(2), 94-100.

Heit, J. A. (2015). Epidemiology of venous thromboembolism. Nature Reviews Cardiology, 12(8), 464.

Hui L, Chan EY (2005). Nurses practices of oral care. Evidence-based practice: Committee for Good Practice Standards of the French Society for Anaesthesiology and Intensive Care (SFAR). Available from URL. www.ncbi.nlm.nih.gov/pubmed/2025141

Kasem , M. (2016) :Assessment of nurses' performance regarding nursing care of patients undergoing blood transfusion. Un published

Master thesis. Faculty of Nursing, Port said University. P.p 83:84. 
Khan, N., Khowaja, K. Z. A., \& Ali, T. S. (2012). Assessment of knowledge, skill and attitude of oncology nurses in chemotherapy administration in tertiary hospital Pakistan. Open Journal of Nursing, 2(2), 97.

Kubilay G and Fesci Erdem H, (2012) "Evaluation of the Status of theNurses Preparing and Administrating CDs,:"Oncology Nurses'Association, Vol. 6, , pp. $7-15$.

Lee, J. A., Grochow, D., Drake, D., Johnson, L., Reed, P., \& van Servellen, G. (2014). Evaluation of hospital nurses' perceived knowledge and practices of venous thromboembolism assessment and prevention. Journal of Vascular Nursing, 32(1), 18-24.

Lee, M. Y., Kim, M. Y., Han, J. Y., Park, J. B., \& Ryu, H. M. (2014). Pregnancyassociated pulmonary embolism during the peripartum period: An 8-year experience at a single center. Obstetrics \& gynecology science, 57(4), 260-265.

Lemone P., Burke K., Dwyer T., Jones T., Moxham L.,(2014):Critical Thinking for Centered CareMedical -Surgical Nursing, $\quad 2^{\text {nd }} \quad$ Ed.,Australian $\quad$ Pearson Group(Pty)Ltd, ch:(37),P:1329 .

Lewis, J. E., \& Pilcher, D. V. (2017). The management of pulmonary embolism. Anaesthesia \& Intensive Care Medicine, 18(3), 126-132.

Lewis S., Dirksen S., Heitkemper M., Bucher L.,(2011):Assessmentand Management of Clinical Problems, Medical -Surgical Nursing, $8^{\text {th }}$ Ed. Mosby Elsevier Inc., section (5),ch:(28), p:578.

Lexshimi, R.G., Daud, F., and Zulkifli, S. (2009): Knowledge, attitudeand practice of nurses in administering oral medication at medicalward, university kebangsaan malaysia medical center.Med \&Health, 4(1): 16-24. 
Linda M. \&Ignatavicius D., (2013): Patient-Centered CollaborativeCare, Medical Surgical Nursing $67^{\text {th }}$ Ed, Canada, Elsevier Inc.,ch:(34),p:663.

Lynn. P., (2015). Taylor's Clinical Nursing Skills., A Nursing Process Approach $4^{\text {th }}$ Ed. Philadelphia: Lippincott Williams \& Wilkins: Pp; 949-950.

Mohammed, S. J., Hamdan, A. S., Ali, A. M., Aaly, A. A., \& Hadi, W. H(2017) . Assessment Nurses Knowledge toward Anticoagulation Therapy for Patients at Blood Disease Ward in Teaching Hospital in Baghdad city.

Morrison, R. (2006). Venous thromboembolism: scope of the problem and the nurse's role in risk assessment and prevention. Journal ofvascular nursing, 24(3), 82-90.

Morrison, R. (2006). Venous thromboembolism: scope of the problem and the nurse's role in risk assessment and prevention. Journal of vascular nursing, 24(3), 8290.

Petter P \&Perry A.,( 2001) fundamental of nursing, $5^{\text {th }}$ Ed., Mosby Inc.,Unit (8),ch:(46),p:1515.

Potter., Patricia, A., \& Perry, A.G. (2013):Fundamental of nursing $.8^{\text {th }}$

Ed .Elsevier mosby. Pp :605:613.

Souza, M. (2015): Effect of planned teaching on knowledge and practice regarding the care of patients receiving anti-coagulant therapyamong the nurses in the intensive care unit in a selected hospital. Asian J. Nur. Edu and Research, 5(3): 351-362.

Oh, H., Boo, S., \& Lee, J. A. (2017). Clinical nurses' knowledge and practice of venous thromboembolism risk assessment and prevention in South Korea: a cross-sectional survey. Journal of clinical nursing, 26(3-4), 427-435. 
Stone, J., Hangge, P., Albadawi, H., Wallace, A., Shamoun, F., Knuttien, M. G., ... \& Oklu, R. (2017). Deep vein thrombosis: pathogenesis, diagnosis, and medical management. Cardiovascular diagnosis and therapy, 7(Suppl 3), S276.

Tapson, F. A., \& Audet, A. M. (2008). Preventing deep veinthrombosis and pulmonary embolism: A practical guide toevaluation and improvement. Center for Outcomes Research, UMass Medical School, Retrieved from www.outcomesumassmed.org/dvt/best practice /-121

Timby B. \& Smith N., (2014): Introductory Medical -Surgical Nursing, $11^{\text {th }}$ Ed, Walters Kluwer, Lippincott Williams and Wilkins, Philadelphia ch:(21),p:317.

$$
\text { أداء الممرضين تجاه وسائل الوقاية من السدة الرئوية فى مستشفيات بورسعيد }
$$

\section{الخــلاصـة}

يعتبر مرض السدة الرئوية ثالث الأمر اض التي تؤدي الى الوفاة بعد امر اض القلب والجلطات و ومنع التجلطات

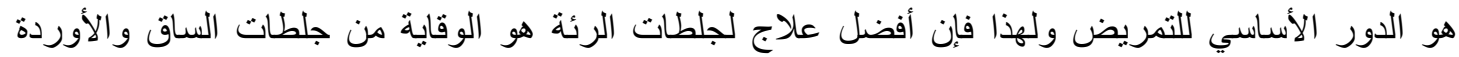

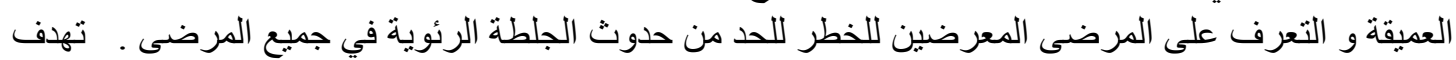

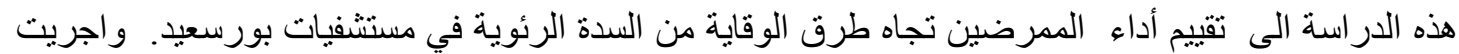

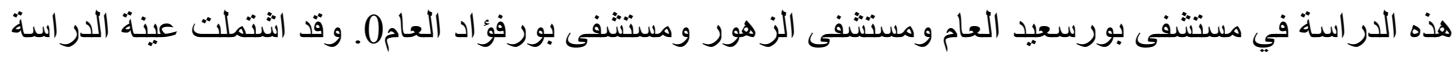

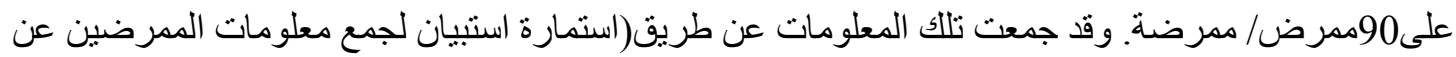
طرق الوقاية من السدة الرئوية واستمارة ملاحظه لتقييم ممارسات الممرضين تجاه طرق الوقائة الوقاية من السدة

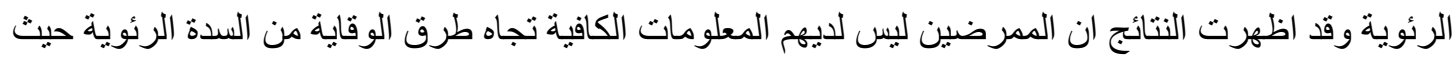

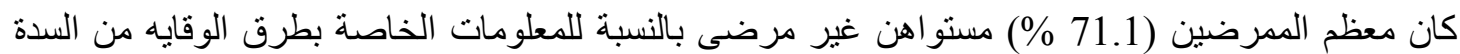

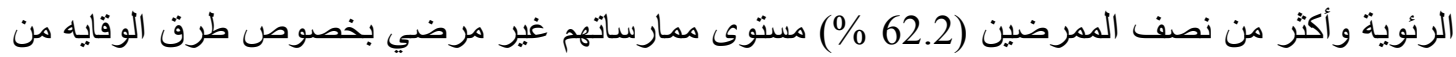

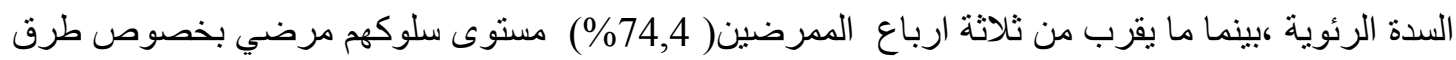

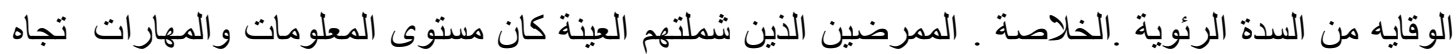

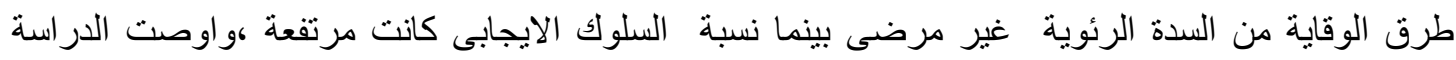

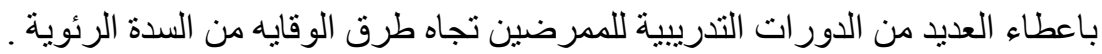

$$
\text { الكلمات المرثدة :- السدة الرئوية _- وسائل الوقاية ـ اداء الممرضين }
$$

